\title{
Assessment of urinary cystatin C levels in HIV-1-infected patients with preserved kidney function
}

\author{
Aleksandra Szymczak ${ }^{1}$, Anna Szymanek-Pasternak ${ }^{2}$, Małgorzata Zalewska ${ }^{1}$, Krzysztof Małyszczak $^{3}$, \\ Weronika Rymer ${ }^{1}$, Brygida Knysz ${ }^{1}$ \\ ${ }^{1}$ Department of Infectious Diseases, Liver Diseases and Acquired Immune Deficiencies, Wroclaw Medical University, \\ Wroclaw, Poland \\ ${ }^{2} 1^{\text {st }}$ Department of Infectious Diseases, The Gromkowski Specialist Regional Hospital, Wroclaw, Poland \\ ${ }^{3}$ Department of Psychiatry, Wroclaw Medical University, Wroclaw, Poland
}

\begin{abstract}
Introduction: Chronic kidney disease in one of the significant chronic conditions in human immunodeficiency virus (HIV)-infected population. The nephrotoxicity of antiretroviral therapy, particularly tenofovir disoproxil fumarate, is the important cause of kidney function impairment. There is a need to find reliable markers of early kidney damage. The aim of the study was to evaluate utility of urinary cystatin C levels as a marker of early kidney tubular damage in HIV-1-infected patients.

Material and methods: A total of 119 HIV-1-infected patients ( 88 males, $74.0 \%$ ) both on antiretroviral therapy (98 individuals, $82.4 \%$ ) and treatment-naïve, without known kidney disease, and 31 healthy volunteers were enrolled. Cystatin $\mathrm{C}$ levels in urine were measured and urine cystatin $\mathrm{C} /$ creatinine ratio (UCCR) was calculated.

Results: Significantly higher levels of urinary cystatin C were observed in HIV-1-infected group and subgroup on antiretroviral therapy with current CD4+ count below 500 cells/ $\mu$ l $(p=0.008$ and $p=0.005$, respectively). In patients with albuminuria, both urinary cystatin C and UCCR were significantly higher $(p=0.0035$ and $p<0.001$, respectively). HIV-1 infection, detectable HIV RNA, low $\mathrm{CD} 4+$ nadir, antiretroviral treatment or its length, use of tenofovir, or protease inhibitors had no influence on urinary cystatin C and UCCR.

Conclusions: Low current CD4+ cell count was the only HIV-1-related factor influencing urinary cystatin $\mathrm{C}$ level. Use of tenofovir or other potentially nephrotoxic antiretroviral drugs did not have any impact on urinary cystatin C levels. Albuminuria was related to higher levels of urinary cystatin $\mathrm{C}$ but the background and relevance of this finding is unclear. Utility of urinary cystatin $\mathrm{C}$ assessment requires further research in large populations.
\end{abstract}

HIV AIDS Rev 2018; 17, 4: 236-242

DOI: https://doi.org/10.5114/hivar.2018.80254

Key words: albuminuria, HIV infection, tenofovir disoproxil fumarate, urinary cystatin C.

Address for correspondence: Dr. Aleksandra Szymczak, Department of Infectious Diseases, Liver Diseases and Acquired Immune Deficiencies, Wroclaw Medical University,

5 Koszarowa St., 51-149 Wroclaw, Poland,

e-mail: ola.szymczak@gmail.com
Article history:

Received: 07.06.2018

Received in revised form: 13.09.2018

Accepted: 14.09.2018

Available online: 26.11 .2018
International Journal of HIV-Related Problems

HIV \& AIDS

R e vi e w 


\section{Introduction}

Successful combined antiretroviral therapy (cART) has substantially prolonged the survival of people living with human immunodeficiency virus (HIV); however, aging HIV-infected population remains at risk of development of long-term consequences of HIV infection, among them chronic kidney disease (CKD) $[1,2]$. Kidney function can be impaired in people living with HIV (PLWH) through multiple causes and distinct pathomechanisms, among them direct action of HIV, concomitant opportunistic infections and non-infectious diseases, adverse effects of antiretroviral drugs or other medicines used in connection with HIV infection, or its complications as well as chronic metabolic disturbances and atherosclerosis [3, 4]. CKD is one of the important factors affecting survival of HIV-infected persons, to a large extent due to the increased risk of cardiovascular disease development [5]. Thus, early detection of kidney function impairment, its close monitoring, and management should be conducted in the standard medical care of all PLWH. The commonly used measure of kidney function is an estimated glomerular filtration rate (eGFR), with the use of different equations, among them the most popular: Cockroft-Gault formula, MDRD (modification of diet in renal disease) formula, or recently considered as the most accurate method of eGFR assessment for HIV-infected population CKD-EPI (CKD epidemiology collaboration) formula [6]. All these measures have some limitations described in detail elsewhere $[7,8]$, and there is still a need for research on more accurate and sensitive parameters of mild kidney function impairment.

Cystatin C (cysC) is polypeptide inhibitor of cysteine proteases. It is synthetized in all nucleated cells and released to the extracellular fluid and blood in stable amounts. CysC is freely filtered in the renal glomerulus, and then reabsorbed and metabolized in the cells of proximal tubules. Eventually, it is excreted in tiny amounts with the urine [9]. Therefore, serum level of cysC (S-cysC) may serve as a marker of glomerular filtration and urinary level (U-cysC) - as a marker of proximal tubular damage [10]. The accuracy of S-cysC levels in diagnosis of CKD has been demonstrated in many publications as better than creatinine serum levels, particularly in special groups of patients, like children, the elderly, or with extremes of body weight, as cysC values are less affected by muscle mass than serum creatinine [11-13]. In recent years, it has been used as the early marker of CKD [14]. $\mathrm{S}$-cysC may be useful as predictor of mortality in elderly population [15]. Utility of S-cysC measures has been also considered in assessment of CKD in HIV-infected individuals $[16,17]$. It has been confirmed as the valuable marker of higher risk of CKD and cardiovascular disease [18], and for predicting all-cause mortality in this group [19].

Urine excretion of cys $\mathrm{C}$ has been assessed in less numerous studies. Because of almost total reabsorption in proximal tubules, increased level of cystatin $\mathrm{C}$ in urine (presented also as calculated urine cystatin $\mathrm{C} /$ creatinine ratio - UCCR) is marker of tubular damage [20-22], among them drug- induced kidney injury [23]. UCCR is considered as a marker of early acute kidney injury [24] but also in a few research papers as a potential marker of chronic kidney disease [25]. For HIV-1 infection one of the current significant clinical problems is long-term nephrotoxicity of the antiretroviral drugs, with tenofovir disoproxil fumarate (TDF), basic nucleoside reverse transcriptase inhibitor used in cART regimens for over 15 years, which is well known as the cause of tubular kidney damage [26].

We investigated the utility of U-cysC for detection of early kidney damage in HIV-1-infected patients, both treated with antiretroviral drugs and treatment-naïve, with preserved kidney function.

\section{Material and methods}

The study was conducted according to the Declaration of Helsinki. All study participants gave written informed consent for the participation in the study.

Presented analysis is a part of larger single-center study assessing kidney function in HIV-1-infected individuals, whereas other results of this study were published previously [27]. The study was conducted on 119 HIV-1-infected subjects, both on antiretroviral treatment and treatment-naïve, with negative history of kidney disease. The control group consisted of 31 HIV-1-negative volunteers, from the Lower Silesia region, Poland, matched for age and gender. All participants were Caucasians, older than 18 years.

The study group consisted of 88 males $(74 \%)$ and $31 \mathrm{fe-}$ males (26\%), aged 23-68 years (mean age, $40.1 \pm 8.9$ years). Clinical data on HIV infection (route of infection, current and nadir CD4+ cell count, HIV RNA level, period of antiretroviral therapy, and regimens used), smoking status, concomitant diseases (hepatitis $\mathrm{C}$ virus $[\mathrm{HCV}]$ infection, hypertension, hyperlipidemia, hyperuricemia, nephrolithiasis) were collected. The exclusion criteria included current diseases of clinical category B or C of the Center for Disease Control and Prevention criteria from 1993, diabetes, uncontrolled arterial hypertension, thyroid diseases, rheumatoid arthritis or other systemic autoimmune diseases treated with corticosteroids, malignancies, fever, acute bacterial, viral or fungal infections, hepatitis B virus (HBV) infection (detectable serum HBsAg), any other known inflammatory states potentially influencing kidney function, a past episode of acute renal failure, and current use of any illicit drugs.

Values of eGFR were calculated based on the values of serum creatinine, using the CKD-EPI formula. Cystatin C levels in serum and urine were measured using an enzyme-linked immunosorbent assay (Quantikine ELISA Human Cystatin C, R\&D Systems Inc., Minneapolis, Minnesota, United States). The sensitivity of the method was $0.03 \mathrm{ng} / \mathrm{ml}$. Urinary albumin levels were measured by an enzyme-linked immunosorbent assay (Albumin ELISA Kit, Immundiagnostik, Bensheim, Germany). Albuminuria was defined as a urine albumin-creatinine ratio greater than $30 \mathrm{mg} / \mathrm{g}$ [28]. Creatinine in urine was measured using colorimetric (Jaffe) reaction (Biolabo, Maizy, France). Urinary cystatin C/creatinine 
ratio (UCCR) was calculated. HIV-1 viral load was determined by real-time PCR assay (COBAS TaqMan HIV-1 test v. 2.0, Roche Diagnostics, Basel, Switzerland). The isolation of HIV-RNA was performed using a system viral nucleic acid kit (Roche Diagnostics). The $\mathrm{CD} 4^{+} \mathrm{T}$ cell count was determined by flow cytometry using FacsCount Becton Dickinson system (BD Biosciences, San Jose, California, United States). Other biochemical tests were measured with the use of standard commercially available methods as a part of routine medical care.

\section{Statistical analysis}

The groups were tested for normal distribution. Mean values were compared by the analysis of variance with the $t$ test and post-hoc Newman-Keuls test. For non-normal distribution, non-parametric Kruskal-Wallis test, Mann-Whitney test, and $\chi^{2}$ test were used. The $p$ values of less than 0.05 were considered statistically significant. Calculations were performed using Statistica 12.0 software for Windows (StatSoft Inc., Tulsa, Oklahoma, United States).

\section{Results}

The characteristics of the HIV-1-infected patients and controls are presented in Table 1.

Among HIV-1-infected patients, in 118 individuals, eGFR level was $>60 \mathrm{ml} / \mathrm{min} / 1.73 \mathrm{~m}^{2}$ and only one subject had mildly decreased eGFR $\left(56 \mathrm{ml} / \mathrm{min} / 1.73 \mathrm{~m}^{2}\right)$. It was 68-year-old woman, with obesity, hyperlipidemia and treated arterial hypertension, with cART for 7 years and boosted protease inhibitor. All control subjects had normal renal function with eGFR above $60 \mathrm{ml} / \mathrm{min} / 1.73 \mathrm{~m}^{2}$. The median values of eGFR in the study subgroups are presented in Table 1.

The majority of the study group was treated with cART $(n=98,82.4 \%)$. Mean period of cART was 4.9 years (range, $<1-13$ years). Current use of potentially nephrotoxic drugs in antiretroviral regimen was as follows: tenofovir disoproxil fumarate (TDF) was used in the cART regimen in 53 subjects (54.1\% of treated patients), protease inhibitors (PI) were used in 70 individuals ( $71.4 \%$ of treated persons). Mean period of treatment with TDF was 3 years (range, 0.2-7.7 years). Additionally, 22 patients were treated with TDF in the past, with mean period of 1.9 years. Total mean exposure on TDF was 2.7 years (range, 0.2-9.1 years). A total of 21 individuals (17.6\%) were not treated with cART, according to international recommendations at the time of conducting the study, or because of newly diagnosed HIV-1 infection and qualification to cART.

A total of $41 \mathrm{HIV}$-1-infected patients had low CD4+ na$\operatorname{dir}(<200$ cells/ $\mu \mathrm{l})$, among them only one subject was not treated with cART.

Table 2 presents levels of cystatin $\mathrm{C}$ in serum and urine, UCCR values in the study group according to cART, and the use of potentially nephrotoxic drugs. Serum cystatin
C levels in HIV-1-infected patients were statistically lower than in the control group $(p<0.001)$. Significantly lower levels were noted also in patients on cART compared to controls $(p=0.002)$ and treatment-naïve compared to controls ( $p=0.008)$. There were no statistically significant differences in serum cystatin $C$ levels in patients treated with certain antiretroviral drugs (TDF or PI/r) versus control subjects.

The differences in urinary cystatin $\mathrm{C}$ levels between HIV-1-infected group, treatment-naïve, and treated with cART compared to control group were not statistically significant ( $p=0.94, p=0.40, p=0.88$, accordingly). Furthermore, levels of urinary cystatin $C$ between treated and not treated subjects did not differ significantly $(p=0.28)$, although in treatment-naïve group, the median level of U-cysC was the highest. The length of antiretroviral therapy did not correlate with U-cysC levels. Potentially nephrotoxic antiretroviral drugs used in cART regimen did not affect the levels of U-cysC. There were no significant correlations between eGFR values and urinary cysC levels in patients treated with different potentially nephrotoxic drugs: TDF $(r=-0.214, p=0.12), \mathrm{PI} / \mathrm{r}(r=-0.097, p=0.42)$, $\mathrm{TDF}+\mathrm{PI} / \mathrm{r}(r=-0.186, p=0.27)$.

UCCR values did not differ significantly between HIV-1-infected subjects and control group $(p=0.17)$, treatment-naive patients and controls $(p=0.27)$, patients on cART and controls $(p=0.19)$, and treatment-naïve vs. treated subjects $(p=0.80)$. There was no significant effect of certain drugs used in CART regimen on UCCR values.

Investigated parameters of HIV-1 infection status included current CD4+ cell count, CD4+ nadir, and HIV-1 RNA levels in patients with detectable viral load (VL). Table 3 summarizes results for total group of HIV-1infected subjects and those treated with cART according to current CD4+ cell count. In both groups, levels of U-cysC were significantly higher in subjects with CD4+ cell count $<500$ cells $/ \mu$ l. Treatment-naïve patients were not analyzed because of small group size. Serum and urinary cysC and UCCR did not differ significantly according to CD4+ nadir in analyzed groups $\geq 200$ vs. $<200$ cells/ $\mu$ l (Table 4 ). Detectable HIV-1 VL either had any significant influence on $\mathrm{S}$-cysC and U-cysC, or UCCR, although this group was small. Untreated group consisted of 21 subjects and among treated patients, detectable VL was low (median, 182 copies/ml) and in majority of patients, only transient, related to blips.

Albuminuria (defined as ACR - albumin/creatinine ratio $>30 \mathrm{mg} / \mathrm{g}$ ) was detected in $16 \mathrm{HIV}-1$-infected subjects (13.4\%), including 14 individuals on cART and 2 treatment-naïve persons. This group included 7 females, 9 males, with median age 41 years (range, 26-63 years). Mean cART length was 5.4 years (range, 1-13 years). Among patients on CART, 11 persons were treated with TDF currently or in the past, and 8 individuals were treated with $\mathrm{PI} / \mathrm{r}$. There were no cases of albuminuria in control group. U-cysC and UCCR were analyzed in 2 subgroups according to ACR value (below $30 \mathrm{mg} / \mathrm{g}$ and above $30 \mathrm{mg} / \mathrm{g}$ ). Table 5 presents the levels of these parameters. Both U-cysC and UCCR were significantly higher in the subgroup with albuminuria. 
Table 1. Characteristics of the study group ([27], modified)

\begin{tabular}{|c|c|c|c|c|c|c|}
\hline \multirow[b]{2}{*}{ Factor } & \multicolumn{3}{|c|}{ HIV-1-infected individuals } & \multirow{2}{*}{$\begin{array}{l}\text { Controls } \\
(n=31)\end{array}$} & \multicolumn{2}{|c|}{$p$ value } \\
\hline & $\begin{array}{c}\text { Total } \\
(n=119)\end{array}$ & $\begin{array}{c}\text { Untreated with } \\
\text { cART } \\
(n=21) \\
17.6 \% \text { of HIV-1- } \\
\text { infected) }\end{array}$ & $\begin{array}{c}\text { Treated } \\
\text { with cART } \\
(n=98), \\
\text { 82.4\% of HIV- } \\
\text { 1-infected) }\end{array}$ & & $\begin{array}{l}\text { HIV-1- } \\
\text { infected } \\
\text { group vs. } \\
\text { controls }\end{array}$ & $\begin{array}{l}\text { Untreated } \\
\text { group } \\
\text { vs. treated } \\
\text { group }\end{array}$ \\
\hline Caucasian race, $n(\%)$ & $119(100)$ & $21(100)$ & $98(100)$ & $31(100)$ & & \\
\hline Males, $n(\%)$ & $88(74.0)$ & $18(85.7)$ & $70(71.4)$ & $21(68.0)$ & NS & NS \\
\hline $\begin{array}{l}\text { Age (years), mean } \pm \text { SD } \\
\text { (range) }\end{array}$ & $\begin{array}{l}40.0 \pm 9.5 \\
(23-68)\end{array}$ & $\begin{array}{l}35.5 \pm 8.0 \\
(26-56)\end{array}$ & $\begin{array}{c}41.0 \pm 9.6 \\
(24-68)\end{array}$ & $\begin{array}{c}40.1 \pm 8.9 \\
(23-68)\end{array}$ & NS & 0.037 \\
\hline $\begin{array}{l}\text { CD4+ count, cells } / \mu l, \\
\text { mean } \pm \text { SD }\end{array}$ & $545 \pm 243$ & $476 \pm 206$ & $560 \pm 249$ & N/A & & NS \\
\hline $\begin{array}{l}\text { CD4+ nadir, cells/ } \mu \mathrm{l}, \\
\text { median (IQR) }\end{array}$ & $\begin{array}{c}272 \\
(119.0-334.0)\end{array}$ & $\begin{array}{c}412 \\
(309.0-491.0)\end{array}$ & $\begin{array}{c}213.5 \\
(91.5-300.5)\end{array}$ & N/A & & $<0.0001$ \\
\hline \multicolumn{7}{|c|}{ CDC category of HIV infection, $n(\%)$} \\
\hline 1 & $64(54.7)$ & $26(50.0)$ & $10(47.6)$ & \multirow{3}{*}{ N/A } & & \multirow{3}{*}{ NS } \\
\hline 2 & 49 (41.9) & $23(44.2)$ & $10(47.6)$ & & & \\
\hline 3 & $4(3.4)$ & $3(5.8)$ & $1(4.8)$ & & & \\
\hline \multicolumn{7}{|l|}{ HIV-1 viral load, $n$ (\%) } \\
\hline $\begin{array}{l}\text { Undetectable } \\
\text { (<34 copies/ml) }\end{array}$ & $85(71.4)$ & 0 & $85(86.7)$ & \multirow[t]{2}{*}{ N/A } & & \multirow[t]{2}{*}{$<0.0001$} \\
\hline Detectable & $34(28.6)$ & $21(100.0)$ & $13(13.3)$ & & & \\
\hline IVDU & $47(40.9)$ & $3(14.3)$ & $44(46.8)$ & 0 & & 0.009 \\
\hline $\mathrm{BMI}, \mathrm{kg} / \mathrm{m}^{2}$, mean $\pm \mathrm{SD}$ & $23.76 \pm 0.32$ & $23.52 \pm 0.78$ & $23.81 \pm 0.36$ & $25.92 \pm 0.64$ & 0.003 & NS \\
\hline \multicolumn{7}{|l|}{ Smoking status, $n(\%)$} \\
\hline Never smoking & $19(16.80)$ & $5(25.00)$ & $14(15.10)$ & $31(100)$ & & \multirow{3}{*}{$<0.0001$} \\
\hline Past smokers & $25(22.10)$ & $1(0.05)$ & $24(25.80)$ & 0 & & \\
\hline Current smokers & $69(61.10)$ & $14(70.00)$ & $55(59.10)$ & 0 & & \\
\hline EGFR, median (IQR) & $\begin{array}{c}108.99 \\
(95.26-117.15)\end{array}$ & $\begin{array}{c}117.36 \\
(128.58-107.20)\end{array}$ & $\begin{array}{c}108.40 \\
(93.07-116.10)\end{array}$ & $\begin{array}{c}104.72 \\
(87.19-111.57)\end{array}$ & 0.06 & 0.001 \\
\hline \multicolumn{7}{|l|}{ Concurrent diseases, $n$ (\%) } \\
\hline Hypertension & $13(11.0)$ & $1(4.8)$ & $12(12.2)$ & $1(3.2)$ & NS & NS \\
\hline Dyslipidemia & $89(74.8)$ & $16(90.4)$ & $73(74.5)$ & $24(77.4)$ & NS & NS \\
\hline Hyperuricemia & $11(9.2)$ & $3(14.3)$ & $9(9.2)$ & $6(19.4)$ & NS & NS \\
\hline HCV infection & $47(39.5)$ & $2(9.5)$ & $45(45.9)$ & $0(0)$ & & 0.002 \\
\hline
\end{tabular}

CART - combined antiretroviral therapy, BMI - body mass index, CDC - Centers for Disease Control and Prevention; EGFR - estimated glomerular filtration rate, HIV-1 - human immunodeficiency virus 1, HCV - hepatitis C virus, IVDU - intravenous drug user, N/A - not applicable, NS - not significant, SD - standard deviation

Proteinuria in general urinalysis was detected in 8 individuals of HIV-1-infected group (6.7\%), all of them were treated with cART (mean period, 5.6 years; range, $1-10$ years), using different regimens (in 7 persons with TDF in current or past regimen), whereas it was absent in all subjects from the control group. U-cysC levels, but not UCCR, were significantly higher in patients with detected proteinuria. Table 5 presents levels of U-cysC and UCCR according to presence of proteinuria in HIV-1-infected subjects.

UCCR was significantly higher in HIV-1-infected females compared to males $(p=0.006)$, whereas in controls this difference was close to statistical significance $(p=0.056)$.
$\mathrm{U}$-cysC levels did not differ according to gender. U-cysC and UCCR were either not correlated with age, body mass index (BMI), smoking, concomitant HCV infection, arterial hypertension, or history of intravenous drug use.

In total of 56 HIV-1-infected subjects, ultrasound examination of kidneys was performed. Features of nephrolithiasis were found in 10 persons, without any relation to cART; 4 subjects were treatment-naïve and only one person was treated with atazanavir, drug potentially inducing nephrolithiasis. Levels of U-cysC were significantly higher ( $p=0.023)$ in subjects with nephrolithiasis compared to individuals with normal ultrasound examination. 
Table 2. Serum and urinary cystatin C levels and urine cystatin C/creatinine ratio values in the study group

\begin{tabular}{|c|c|c|c|c|c|c|c|}
\hline \multirow{3}{*}{ Factor } & \multicolumn{6}{|c|}{ HIV-1-infected individuals $(n=119)$} & \multirow{3}{*}{$\begin{array}{l}\text { Controls } \\
(n=31)\end{array}$} \\
\hline & \multirow[b]{2}{*}{ Total } & \multirow{2}{*}{$\begin{array}{l}\text { Untreated } \\
\text { with cART } \\
(n=21)\end{array}$} & \multicolumn{4}{|c|}{ Treated with CART } & \\
\hline & & & $\begin{array}{c}\text { Total } \\
(n=98)^{1}\end{array}$ & $\begin{array}{c}\text { TDF } \\
(n=53)\end{array}$ & $\begin{array}{c}\mathrm{PI} / \mathrm{r} \\
(n=70)\end{array}$ & $\begin{array}{l}\text { TDF+PI/r } \\
(n=37)\end{array}$ & \\
\hline $\begin{array}{l}\text { Serum cystatin C (mg/l), } \\
\text { median (IQR) }\end{array}$ & $\begin{array}{c}0.585 \\
(0.300-0.810)\end{array}$ & $\begin{array}{c}0.525 \\
(0.333-0.781)\end{array}$ & $\begin{array}{c}0.598 \\
(0.295-0.810)\end{array}$ & $\begin{array}{c}0.660 \\
(0.300-0.845)\end{array}$ & $\begin{array}{c}0.628 \\
(0.330-0.845)\end{array}$ & $\begin{array}{c}0.720 \\
(0.360-0.920)\end{array}$ & $\begin{array}{c}0.775 \\
(0.710-0.840)\end{array}$ \\
\hline $\begin{array}{l}\text { Urine cystatin C (ng/ml), } \\
\text { median (IQR) }\end{array}$ & $48(22-96)$ & $57(38-95)$ & $45(22-96)$ & $54(22-98)$ & $45(22-72)$ & $52(22-98)$ & $48(27-98)$ \\
\hline UCCR, median (IQR) & $\begin{array}{c}0.436 \\
(0.289-0.621)\end{array}$ & $\begin{array}{c}0.450 \\
(0.309-0.599)\end{array}$ & $\begin{array}{c}0.435 \\
(0.286-0.622)\end{array}$ & $\begin{array}{c}0.443 \\
(0.296-0.661)\end{array}$ & $\begin{array}{c}0.446 \\
(0.295-0.626)\end{array}$ & $\begin{array}{c}0.480 \\
(0.340-0.661)\end{array}$ & $\begin{array}{c}0.331 \\
(0.258-0.538)\end{array}$ \\
\hline
\end{tabular}

${ }^{1}$ Sum of the patients treated with listed drugs is larger than total group, as separated subgroups partially overlap.

CART - combined antiretroviral therapy, HIV-1 - human immunodeficiency virus $1, I Q R$ - interquartile range, PI/r-protease inhibitor boosted with ritonavir, $T D F$ - tenofovir disoproxil fumarate, UCCR - urine cystatin C/creatinine ratio

Table 3. Serum and urinary cystatin C levels and urine cystatin C/creatinine ratio according to current CD4+ cell count

\begin{tabular}{|c|c|c|c|c|c|c|}
\hline \multirow[b]{2}{*}{ Factor } & \multicolumn{3}{|c|}{ Total HIV-1-infected group $(n=117)^{\mathrm{a}}$} & \multicolumn{3}{|c|}{ Group treated with cART $(n=96)^{a}$} \\
\hline & $\begin{array}{c}\text { CD4+ } \\
\geq 500 \text { cells } / \mu \mathrm{l}\end{array}$ & $\begin{array}{c}\text { CD4+ } \\
<500 \text { cells } / \mu \mathrm{l}\end{array}$ & $p$ value & $\begin{array}{c}\text { CD4+ } \\
\geq 500 \text { cells } / \mu \mathrm{l}\end{array}$ & $\begin{array}{c}\text { CD4+ } \\
<500 \text { cells } / \mu \mathrm{l}\end{array}$ & $p$ value \\
\hline $\begin{array}{l}\text { Serum cystatin C }(\mathrm{mg} / \mathrm{ml}) \text {, } \\
\text { median (IQR) }\end{array}$ & $\begin{array}{c}605 \\
(295-730)\end{array}$ & $\begin{array}{c}600 \\
(315-845)\end{array}$ & 0.6 & $\begin{array}{c}585 \\
(295-730)\end{array}$ & $\begin{array}{c}625 \\
(270-920)\end{array}$ & 0.66 \\
\hline $\begin{array}{l}\text { Urinary cystatin C (ng/ml), } \\
\text { median (IQR) }\end{array}$ & $\begin{array}{c}40 \\
(19-69) \\
\end{array}$ & $\begin{array}{c}57 \\
(37-110)\end{array}$ & 0.008 & $\begin{array}{c}35 \\
(19-65)\end{array}$ & $\begin{array}{c}58.5 \\
(37-110)\end{array}$ & 0.005 \\
\hline UCCR, median (IQR) & $\begin{array}{c}0.421 \\
(0.283-0.591)\end{array}$ & $\begin{array}{c}0.449 \\
(0.324-0.688)\end{array}$ & 0.11 & $\begin{array}{c}0.397 \\
(0.281-0.589)\end{array}$ & $\begin{array}{c}0.443 \\
(0.340-0.692)\end{array}$ & 0.11 \\
\hline$n$ & 64 & 53 & & 54 & 42 & \\
\hline
\end{tabular}

aln 2 patients current $C D 4^{+}$count was unavailable.

CART - combined antiretroviral therapy, HIV-1 - human immunodeficiency virus $1, I Q R$-interquartile range, UCCR - urine cystatin C/Creatinine ratio

\section{Discussion}

HIV-1-infected patients included in the presented study had normal kidney function, and eGFR level in the study group was even better than in the controls. Moreover, levels of serum cystatin C in the HIV-1-infected persons were significantly lower than in seronegative volunteers, which confirms well preserved renal function [29]. It was despite long-lasting antiretroviral treatment, along with exposure on potentially nephrotoxic drugs.

Significantly higher levels of U-cysC (but not UCCR) were demonstrated in individuals with current CD4+ cell count below normal values $(<500$ cells/ $\mu \mathrm{l})$ suggesting an impact of persistent, although relatively mild immune deficit on kidney damage. On the other hand, low CD4+ nadir was not associated with the risk of kidney injury development. As all, except one, patients with low CD4+ nadir $(<200$ cells/ $\mu \mathrm{l})$ were treated with cART, it seems that due to successful antiretroviral therapy, kidney injury reflected by high urinary excretion of cysC may be reversible.

Except current CD4+ cell count, we did not find any impact of factors related to HIV-1 infection on U-cysC level or UCCR. Slightly higher levels of U-cysC in HIV-1-infected group compared to controls were not significant. Moreover, detectable VL did not significantly influenced levels of U-cysC, and the use of cART did not change U-cysC. Treatment with potentially nephrotoxic antiretroviral drugs, as TDF or PI, was not associated with tubular damage assessed with $\mathrm{U}$-cysC or UCCR. No differences found in U-cysC levels in HIV-1-infected group, treated or not treated with TDF or PI, also compared to healthy controls, suggest that TDF-associated tubulopathy is an uncommon adverse effect. Jaafar et al. demonstrated utility of UCCR in confirming or excluding Fanconi syndrome (FS) in HIV-1-infected patients treated with TDF, with suspected FS [30]. However, our results cannot be directly compared to Jaafar's analysis because of different inclusion criteria in our study; Jaafar et al. included only the patients with known kidney injury. It may show that UCCR is not useful as a screening test in patients with normal kidney function.

One of the findings in our study was the increased excretion of cysC in patients with detected albuminuria. Albuminuria is well known marker of glomerular pathologies but may be also an indicator of injury of proximal renal tubules, particularly in early diabetic nephropathy, drug-related kidney injury, or AKI [31]. However, this phenomenon may be not an indicator of kidney injury but rather a result of the competition for common transport mechanism in tubular absorp- 
Table 4. Serum and urinary cystatin $\mathrm{C}$ levels and urine cystatin C/creatinine ratio according to CD4+ cell count nadir

\begin{tabular}{|c|c|c|c|c|c|c|}
\hline \multirow[b]{2}{*}{ Factor } & \multicolumn{3}{|c|}{ Total HIV-1-infected group $(n=108)^{\mathrm{a}}$} & \multicolumn{3}{|c|}{ Group treated with cART $(n=87)^{\mathrm{a}}$} \\
\hline & $\begin{array}{l}\text { CD4+ nadir } \\
\geq 200 \text { cells } / \mu l\end{array}$ & $\begin{array}{l}\text { CD4+ nadir } \\
<200 \text { cells } / \mu \mathrm{l}\end{array}$ & $p$ value & $\begin{array}{c}\text { CD4+ nadir } \\
\geq 200 \text { cells } / \mu \mathrm{l}\end{array}$ & $\begin{array}{l}\text { CD4+ nadir } \\
<200 \text { cells } / \mu l\end{array}$ & $p$ value \\
\hline $\begin{array}{l}\text { Serum cystatin C (mg/ml), } \\
\text { median (IQR) }\end{array}$ & $\begin{array}{c}540 \\
(297.0-782.0)\end{array}$ & $\begin{array}{c}630 \\
(300.0-920.0)\end{array}$ & 0.48 & $\begin{array}{c}540 \\
(290.0-805.0)\end{array}$ & $\begin{array}{c}655 \\
(312.5-922.5)\end{array}$ & 0.41 \\
\hline $\begin{array}{l}\text { Urinary cystatin C (ng/ml), } \\
\text { median (IQR) }\end{array}$ & $\begin{array}{c}44 \\
(21.0-95.0)\end{array}$ & $\begin{array}{c}50 \\
(23.0-100.0)\end{array}$ & 0.52 & $\begin{array}{c}42 \\
(20.5-70.0)\end{array}$ & $\begin{array}{c}49 \\
(22.5-104.5)\end{array}$ & 0.31 \\
\hline UCCR, median (IQR) & $\begin{array}{c}0.433 \\
(0.286-0.594)\end{array}$ & $\begin{array}{c}0.48 \\
(0.320-0.688)\end{array}$ & 0.26 & $\begin{array}{c}0.414 \\
(0.281-0.559)\end{array}$ & $\begin{array}{c}0.467 \\
(0.308-0.690)\end{array}$ & 0.23 \\
\hline$n$ & 67 & 41 & & 47 & 40 & \\
\hline
\end{tabular}

aData of CD4+ nadir was available for 108 HIV-1-infected patients only.

CART - combined antiretroviral therapy, HIV-1 - human immunodeficiency virus $1, I Q R$-interquartile range, UCCR - urine cystatin C/Creatinine ratio

Table 5. Serum and urinary cystatin C levels and urine cystatin C/creatinine ratio according to albumin-creatinine ratio and proteinuria in HIV-1 infected subjects

\begin{tabular}{l|c|c|c|c|c|c}
\hline \multirow{2}{*}{ Factor } & \multicolumn{3}{|c|}{ ACR } & \multicolumn{3}{c}{ Proteinuria } \\
\cline { 2 - 7 } & $\leq 30 \mathrm{mg} / \mathrm{g}$ & $>30 \mathrm{mg} / \mathrm{g}$ & $p$ value & Absent & Present & $p$ value \\
\hline $\begin{array}{l}\text { Serum cystatin C (mg/ml), } \\
\text { median (IQR) }\end{array}$ & $\begin{array}{c}555 \\
(297.0-782.0)\end{array}$ & $\begin{array}{c}722 \\
(420.0-1065.0)\end{array}$ & 0.133 & $\begin{array}{c}540 \\
(297.0-810.0)\end{array}$ & $\begin{array}{c}722.5 \\
(512.5-992.5)\end{array}$ & 0.210 \\
\hline $\begin{array}{l}\text { Urinary cystatin C (ng/ml), } \\
\text { median (IQR) }\end{array}$ & $\begin{array}{c}42 \\
(21.0-69.0)\end{array}$ & $\begin{array}{c}103.5 \\
(51.0-175.5)\end{array}$ & 0.004 & $\begin{array}{c}44.0 \\
(22.0-72.0)\end{array}$ & $\begin{array}{c}150.0 \\
(53.5-200.0)\end{array}$ & 0.006 \\
\hline UCCR, median (IQR) & $\begin{array}{c}0.41 \\
(0.280-0.570)\end{array}$ & $\begin{array}{c}0.72 \\
(0.520-1.110)\end{array}$ & $<0.001$ & $\begin{array}{c}0.436 \\
(0.289-0.594)\end{array}$ & $\begin{array}{c}0.7 \\
(0.284-1.376)\end{array}$ & 0.176 \\
\hline$n$ & 103 & 16 & & 111 & 8 & \\
\hline
\end{tabular}

$A C R$ - albumin-creatinine ratio, IQR - interquartile range, $U C C R$ - urine cystatin $C /$ creatinine ratio

tion of low-molecular weight (LMW) proteins [32]. Research of Nejat et al. demonstrated on animal model that urinary excretion of markers of acute kidney injury such as cysC and neutrophil gelatinase-associated lipocalin (NGAL), which are LMW proteins, increases with induced albuminuria and proteinuria [33]. Therefore, our observation cannot serve as a proof for utility of U-cysC measurement in detecting of kidney injury. The results of urinary biomarkers measurements should be interpreted with caution in presence of albuminuria. Further research on this phenomenon including large human populations of patients is needed to determine if increased urinary excretion of cysC is related to proximal tubular injury or rather receptor competition of LMW proteins. Modification of threshold of U-cysC detection for preexisting albuminuria may be also required.

Significantly higher values of UCCR, but not U-cysC levels, in females compared to males probably may be explained by gender-related differences in muscle mass and creatinine excretion rates. Lower levels of urinary creatinine in females may affect results of calculated urinary cystatin C/urinary creatinine ratio [34].

Detected nephrolithiasis was correlated with higher levels of U-cysC, which may be the result of nephrolithiasis-related tubulopathy [35]. However, the small number of individuals with nephrolithiasis does not allow on any more detailed anal- ysis of these cases in terms of any HIV-associated risk factors (e.g., treatment with atazanavir) for nephrolithiasis.

Data concerning U-cysC in assessment of chronic tubular damage due to different reasons are very scarce. Our initial observations in HIV-1-infected patients indicate the need for further research of U-cysC utility for assessment of chronic kidney injury in HIV-1-infected patients. We did not find any relation between the use of TDF and this biomarker of tubular damage. Increased excretion of cysC with urine in patients with decreased CD4+ cell count suggests the influence of current, even mild immune deficit on kidney function.

Limitations of the presented study include relatively small group of patients, particularly cART-naïve subgroup, probably too small to demonstrate an impact of TDF use on very subtle markers of early kidney damage and development of tubulopathy. Moreover, the investigated group was heterogenic for length of cART and used regimens of antiretroviral drugs.

\section{Conclusions}

Low current CD4+ cell count was the only HIV-1-related factor influencing urinary cystatin $\mathrm{Clevel}$ found in our study. Tubular damage due to TDF or other potentially nephrotoxic 
antiretroviral drugs, assessed by urinary cystatin C measurement, seems to be uncommon in patients without clinically evident chronic kidney disease. Albuminuria was related to higher levels of urinary cystatin C in HIV-1-infected subjects; however, the finding needs further research to assess its origin and clinical relevance. Utility of U-cysC in assessment of early kidney function impairment needs research on larger groups of patients and long-term observations, for both types of results: as U-cysC level itself and UCCR.

\section{Conflict of interest}

The authors declare no potential conflicts of interest with respect to the research, authorship, and/or publication of this article.

\section{References}

1. Fernando SK, Finkelstein FO, Moore BA, et al. Prevalence of chronic kidney disease in an urban HIV infected population. Am J Med Sci 2008; 335: 89-94.

2. Rasmussen LD, May MT, Kronborg G, et al. Time trends for risk of severe age-related diseases in individuals with and without HIV infection in Denmark: a nationwide population-based cohort study. Lancet HIV 2015; 2: e288-298.

3. Szczech LA, Gupta SK, Habash R, et al. The clinical epidemiology and course of the spectrum of renal diseases associated with HIV infection. Kidney Int 2004; 66: 1145-1152.

4. Mocroft A, Lundgren JD, Ross M, et al. Development and validation of a risk score for chronic kidney disease in HIV infection using prospective cohort data from the D:A:D study. PLoS Med 2015; 12: e1001809.

5. Hentzien M, Dramé M, Allavena C, et al. Impact of age-related comorbidities on five-year overall mortality among elderly HIVinfected patients in the late HAART era - role of chronic renal disease. J Nutr Health Aging 2016; 20: 408-414.

6. Cristelli MP, Cofán F, Rico N, et al. Estimation of renal function by CKD-EPI versus MDRD in a cohort of HIV-infected patients: a cross-sectional analysis. BMC Nephrol 2017; 18: 58.

7. KDIGO 2012 Clinical practice guideline for the evaluation and management of chronic kidney disease. Kidney Int Suppl 2013; 3: 136-150.

8. Cirillo M, Anastasio P, De Santo NG. Relationship of gender, age, and body mass index to errors in predicted kidney function. Nephrol Dial Transplant 2005; 20: 1791-1798.

9. Mussap M, Plebani M. Biochemistry and clinical role of human cystatin C. Crit Rev Clin Lab Sci 2004; 41: 467-550.

10. Westhuyzen J. Cystatin C: a promising marker and predictor of impaired renal function. Ann Clin Lab Sci 2006; 36: 387-394.

11. Roos JF, Doust J, Tett SE, et al. Diagnostic accuracy of cystatin C compared to serum creatinine for the estimation of renal dysfunction in adults and children - a meta-analysis. Clin Biochem 2007; 40: 383-391.

12. Garasto S, Fusco S, Corica F, et al. Estimating glomerular filtration rate in older people. Biomed Res Int 2014; 2014: 916542.

13. Mysliwiec P, Jasiewicz P, Hady HR, et al. Creatinine or cystatin C which is a better index of renal function in morbid obesity? Adv Med Sci 2013; 58: 376-381.

14. Shlipak MG, Mattes MD, Peralta CA. Update on cystatin C: incorporation into clinical practice. Am J Kidney Dis 2013; 62: 595-603.

15. Larsson A, Helmersson J, Hansson LO, et al. Increased serum cystatin $\mathrm{C}$ is associated with increased mortality in elderly men. Scand J Clin Lab Invest 2005; 65: 301-305.
16. Jones CY, Jones CA, Wilson IB, et al. Cystatin C and creatinine in an HIV cohort: the nutrition for healthy living study. Am J Kidney Dis 2008; 51: 914-924.

17. Mocroft A, Wyatt C, Szczech L, et al. INSIGHT SMART Study Group. Interruption of antiretroviral therapy is associated with increased plasma cystatin C. AIDS 2009; 23: 71-82.

18. Odden MC, Scherzer R, Bacchetti P, et al. Cystatin C level as a marker of kidney function in human immunodeficiency virus infection: the FRAM study. Arch Intern Med 2007; 167: 2213-2219.

19. Choi A, Scherzer R, Bacchetti P, et al. Cystatin C, albuminuria, and 5 -year all-cause mortality in HIV-infected persons. Am J Kidney Dis 2010; 56: 872-882.

20. Herget-Rosenthal S, Van Wijk JAE, et al. Increased urinary cystatin C reflects structural and functional renal tubular impairment independent of glomerular filtration rate. Clin Biochem 2007; 40: 946-951.

21. Conti M, Moutereau S, Zater M, et al. Urinary cystatin C as a specific marker of tubular dysfunction. Clin Chem Lab Med 2006; 44: 288-291.

22. Uchida K, Gotoh A. Measurement of cystatin $C$ and creatinine in urine. Clin Chim Acta 2002; 323: 121-128.

23. Dieterle F, Perentes E, Cordier A, et al. Urinary clusterin, cystatin C, beta-2-microglobulin and total protein as markers to detect drug-induced kidney injury. Nat Biotechnol 2010; 28: 463-469.

24. Park MY, Choi SJ, Kim JK, et al. Urinary cystatin C levels as a diagnostic and prognostic biomarker in patients with acute kidney injury. Nephrology 2013; 18: 256-262.

25. Koyama K, Okajima T, Tanabe M, et al. Japan Obesity and Metabolic Syndrome Study (JOMS) Group. Urinary cystatin C as a potential risk marker for cardiovascular disease and chronic kidney disease in patients with obesity and metabolic syndrome. Clin J Am Soc Nephrol 2011; 6: 265-273.

26. De la Calle GM, Pulido F, Sánchez-Conde M, et al. Long-term comparative and prospective cohort study of renal function in patients with HIV infection treated with tenofovir disoproxil fumarate. HIV AIDS Rev 2017; 16: 77-83.

27. Szymanek-Pasternak A, Szymczak A, Zalewska M, et al. Risk factors for chronic kidney disease do not influence the serum levels of asymmetric dimethylarginine in HIV-1-infected patients without significant renal disease. Pol Arch Med Wewn 2016; 126: 672-680.

28. Szczech LA, Grunfeld C, Scherzer R, et al. Microalbuminuria in HIV infection. AIDS 2007; 21: 1003-1009.

29. Jaroszewicz J, Wiercinska-Drapalo A, Lapinski TW, et al. Does HAART improve renal function? An association between serum cystatin C concentration, HIV viral load and HAART duration. Antivir Ther 2006; 11: 641-645.

30. Jaafar A, Séronie-Vivien S, Malard L, et al. Urinary cystatin C can improve the renal safety follow-up of tenofovir-treated patients. AIDS 2009; 23: 257-259.

31. Comper WD, Russo LM. The glomerular filter: an imperfect barrier is required for perfect renal function. Curr Opin Nephrol Hypertens 2009; 18: 336-342.

32. Thielemans N, Lauwerys R, Bernard A. Competition between albumin and low-molecular-weight proteins for renal tubular uptake in experimental nephropathies. Nephron 1994; 66: 453-458.

33. Nejat M, Hill JV, Pickering JW, et al. Albuminuria increases cystatin C excretion: implications for urinary biomarkers. Nephrol Dial Transplant 2012; 27: iii96-iii103.

34. Ix JH, De Boer IH, Wassel CL, et al. Urinary creatinine excretion rate and mortality in persons with coronary artery disease: The Heart and Soul Study. Circulation 2010; 121: 1295-1303.

35. Jaeger P, Portmann L, Ginalski JM, et al. Tubulopathy in nephrolithiasis: consequence rather than cause. Kidney Int 1986; 29: 563-571. 